\title{
A TRADIÇÃO E O DESEJO NA OBRA DO ESCRITOR MINEIRO LUIZ CANABRAVA
}

\author{
Leonardo Tadeu Nogueira Palhares* \\ Ivana Ferrante Rebello
}

RESUMO: Publicada em 1954, pela editora José Olympio, Sangue de Rosaura, coletânea de contos do escritor Luiz Canabrava, apresenta traços de homoerotismo. Embora vencedor de um prêmio literário nacional, o livro teria pouca notabilidade e repercussão. As representações de violência, dor e aprisionamento, constantes nas narrativas, conjugam-se às expressões de um desejo homoerótico represado. Apontado como um dos percussores da literatura homossexual brasileira, a partir dos anos 1960, o escritor mineiro de Curvelo já delineava situações em que a figura masculina viril não só entra em decadência, como também aponta para a expressão do desejo sexual entre dois homens. Em vista de resgatar este autor esquecido, porém com importância para a literatura LGBTT de meados do século XX, investigamos como Canabrava, já em sua estreia, traz o tema do homoerotismo, e como isso pode ter sido uma das suas razões para o seu apagamento na historiografia literária brasileira.

PALAVRAS-CHAVE: Homoerotismo; Literatura de Minas Gerais; Luiz Canabrava; Sangue de Rosaura;

Publicado em 1954 pela Editora José Olympio, Sangue de Rosaura, coletânea de contos, marca a estreia em livro do autor mineiro de Curvelo, Luiz Carlos Olivé Canabrava. A obra, oriunda da vitória de um concurso literário — o Prêmio Fábio Prado, de 1953 reúne dez contos, e é intitulada pelo nome de um deles, cuja narrativa também abre o livro. Este livro apresenta alguns contos já publicados em jornais e outros inéditos. De acordo com a seção "Panorama Literário" do folhetim Letras e Artes, de $1^{\circ}$ de junho de 1954, o

\footnotetext{
* Mestrando em Letras/Estudos Literários pelo Programa de Pós-Graduação em Letras/Estudos Literários da Universidade Estadual de Montes Claros (Unimontes).

${ }^{*}$ Doutora em Literatura Brasileira pela Puc-MG. Professora do Departamento de Comunicação e Letras da Universidade Estadual de Montes Claros (Unimontes).
} 
prêmio da categoria "conto" foi o único em que o vencedor foi conhecido sem que a decisão fosse unânime: enquanto que os jurados Lygia Fagundes Telles e Paulo Cesar da Silva votaram em Luiz Canabrava, João de Sousa Ferraz optou pelo livro "Plá”, de Guido Wilmar Sassi (cf. PANORAMA..., 1954, p. 11).

A partir disso, a publicação de Sangue de Rosaura começou a ser tratada como notícia pelos periódicos. No Flan - O Jornal da Semana de 6-12 de junho de 1954, metade de uma página inteira por Mauritônio Meira foi dedicada para a notícia da vitória de Luiz Canabrava no concurso, com o seu rosto em destaque (cf. MEIRA, 1954, p. 6). Em 29 de junho de 1954, o folhetim Letras e Artes anunciou que a publicação do livro seria feita pela editora José Olympio, e até parabeniza a editora pelo feito (cf. PANORAMA..., 1954, p. 10). Em outra nota, em 17 de agosto do corrente ano, o mesmo folhetim na mesma seção anuncia que o livro está em impressão e que deve ser publicado até o final do ano (cf. PANORAMA..., 1954, p. 11).

Após esta espécie de "expectativa” ante a publicação do livro, pouco se lê depois sobre Sangue de Rosaura. Em termos de críticas escritas "no calor da hora", com mais detalhamentos, temos duas produções: a de Reinaldo Dias e a de Nelson Werneck Sodré. Podemos perceber que os dois periódicos, nos quais as críticas foram publicadas, não tinham anteriormente uma relação mais estreita com a obra de Canabrava, quanto à publicação de seus contos, o que indica certo afastamento de ambos em relação ao autor. Talvez por isso tais críticas possuam ressalvas à produção vencedora do Prêmio Fábio Prado de 1953 no que tange a apontar para uma "qualidade" na obra de Luiz Canabrava.

Nelson Werneck Sodré, conhecido por ser o autor de História da Imprensa no Brasil, faz uma análise que, já pelo seu título — "Sinais de Derrota" — denota uma percepção negativa para com a obra de Luiz Canabrava: 


\section{SINAIS D
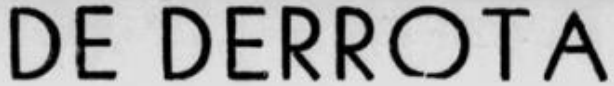 \\ MELSON WERXECK SODRE'}

I) Os premies literarios que ainda tém vigeneia, em nosse pais,

A mâe golpeava-o rü cabeça e. queimando o pé no borratho fu megante, ficou nais rafvosa, $P_{0}$. tem. Daí năo compensar o tempo perdide em analisar o provinctanisme que os cireunda. Irremedlavelmente, a subordinacho gease invariavel a criterios pessoais, as injuncóes de grupos e i.iptes outros tristes e apagatos detalhes que envolvem o quadro. Nao e materla que mereça diseussio, uma vez que dessa diseussáo pruce pode resultar de benefirie. Ru tude, naqueles premies. verifieatse o reflexs do que tem de carateristica a nossa vida literarla. Ate mesmo o singular culte ao medalhảe, aparentemente tâo distante das cogitaçós de eseritor, num melo $\mathrm{cm}$ que a irreverencla se aprevena com papel de relevo.

Fm malo de 1954 reunlu-se a combsão destinada a verifi. car a facm eaberla um dos premios literarios vigentes, por sinal um do. poucos que se deslacam, guardadas as proporḉes, do baixe nivel materlal em que se irmanam quave todes os outros. A cemissáo náo Importa, - ja nem sequer nos lembrames dos seus somponentes e, ceriamente, entre eles teria existido sente seus somponentes e, certamente, entre eles teria existido sente
di-iada tie capacidade' para Julgar, em termos de literaura. Re. suttou o premio para o sr. Luin Canabrava, eujo volume de conto. apareceu ha poueo: "Sangue de Rosaura"

Nào est amos em condicôes de discutir se o premio fol justo ou nub. E se estivessemos nūo nos dariamos a esse trabatho, 0 que nos intere:sa, nesta oporque nos intcre:sa, nesta opor- tor e um bom ou um mau contista.

Segue-se "Maria Bamba" que é uma historia de assombramento. Depois vem "Noite" conto que, segundo nos informa gou o caldeirio chelo de amsu

gou o caldeir

ainda quente. "Carma, sa Maria! Carm.

sú Murla - gritou Chíca

"O ferro fez um barulho sur. do na cabeca do bobo. Ele catu de borco, ficcu quicto e o sangue comecou a escorrer no chấ de terra betida.

"Crus! tatu-peba focinha nas sepulturas:

Passemos ao conto sezuinte. "O Buraco". Trata-se de uma pobre que é atormentada por uma virago, que domina a familia porque a sustenta. Sâo todos criaturas vencidas, que a vida destrocou. A vitima acabu por ter um fitho, que nifo vé. pois é retirado de seu leito quando a máe permanecta aitida inconsciente. A tirana the diz que nasceu e que o enterra.

(Conelui na s.a paz

FIGURA 1: Detalhe do fac-símile da publicação do texto "Sinais de Derrota" de Nelson Werneck Sodré sobre Sangue de Rosaura. FONTE: SODRÉ, Nelson Werneck. "Sinais de Derrota". IN: Pensamento e Arte. São Paulo, p. 3 e 5,25 de dezembro de 1954 .

Ao iniciar a crítica, Sodré é grave ao desdenhar dos concursos literários, especialmente ao Fábio Prado que, sem citá-lo, considera-o com destaque pelo "baixo nível material em que se irmanam quase todos os outros [concursos]". O crítico diz que pretende não julgar a premiação, nem a obra e nem o autor, mas sim "alguns sintomas curiosos que vão surgindo, já de algum tempo a esta parte, na produção dos nossos escritores, denunciando suas origens profundas e gerais" (SODRÉ, 1954, p. 3).

Sodré passa a resumir a obra, afirmando que pretende não analisar a forma, que “não merece reparo algum", mas o conteúdo, de forma a querer provar um padrão que há com outras obras da época. Resume o primeiro conto, "Sangue de Rosaura"; reduz "Maria Bambá" a "uma história de assombramento", e prossegue com "Noite" e os contos conforme a ordem do livro, a resumi-los e exemplificá-los com trechos. Com o fim dos resumos, Sodré diz que propôs mostrar o que a cada um deles era o "essencial", que iria apontar para "um certo sentido comum". Ao divagar mais uma vez que a qualidade "do sr. Luiz 
Canabrava [...] não está em causa” (cf. SODRÉ, 1954, p. 3 e 5), questiona, retoricamente, qual seria o laço comum entre os contos. E logo responde:

Parece, e fica mais ou menos claro através dos resumos apresentados, que é a intenção, plenamente realizada, de apresentar criaturas anormais, infelizes, idiotas, criminosas, à margem do habitual, do costumeiro. Vimos, uma por uma, as suas histórias. Trata-se de crimes, paixões alucinadas, de assombramentos, de desvios patológicos, de descomedimentos, de amargura profunda. E de tédio. A palavra, aliás, é repetida, o que tem uma certa importância, pois a palavra loucura aparece poucas vezes, e as personagens são quase todas loucas (SODRÉ, 1954, p. 5).

O crítico afirma, na sequência, que traços como a demência, o crime, a paixão desvairada e o assombramento, se insistentes na literatura, passam a constituir como o são, se repetentes no meio literário. E afirma que isto está acima de saber se Canabrava é ou não um bom escritor: isto é um reflexo da própria vida que, para o crítico, preocupam-se demais "com o que está morrendo" e, portanto, vemos "pessimismo, o seu tom impregnado de mágoa e até de rancor. E de tédio também”. E então explica o título da crítica: "São sintomas visíveis, sinais evidentes de derrota, em todo caso", e completa: "[u]ma literatura que se vira preponderantemente para o conteúdo da derrota não faz mais do que anunciar a derrota de tudo que a gerou e a mantém” (SODRÉ, 1954, p. 5).

Sodré parece ter com a obra de Canabrava uma leitura pautada pela Sociologia da Literatura, isto é, apresenta uma visão determinista de como o epicentro (a obra em questão) reflete-se no todo, e também o processo inverso. O texto literário, assim, "não seria um simples reflexo de uma consciência real e dada, mas a conscientização e a concretização das tendências de um grupo social" (BOTELHO E FERREIRA, 2007, p. 17).

Podemos ver que a crítica de Nelson Werneck Sodré não aponta para uma má qualidade da obra de Luiz Canabrava ante ao que se esperava de um título que se compunha da palavra "derrota" classificando um livro "vencedor" de um concurso. Ele percebe o livro como uma obra; ressalta que os contos coligados transmitem uma ideia, e persevera nesta perspectiva, embora não enumere com quais pares a literatura canabraviana possa 
fazer. Um ponto a ressaltar é que Sodré não busca posicionar Canabrava na questão literária do dia a visar alguma qualidade em sua escrita, mas sim em algo que o livro do escritor curvelano pudesse ter em comum não só entre os textos, mas também enquanto obra, comparativamente às demais existentes.

$\mathrm{Na}$ pesquisa no site da Biblioteca Nacional, o que temos sobre Sangue de Rosaura e as produções literárias de Luiz Canabrava limita-se entre o fim da década de 1940 até a metade dos anos 1950. Após isso, veremos algum destaque para a sua produção enquanto escritor (como pintor Canabrava ainda teria alguma divulgação) e, na década de 1960, teremos parcas divulgações a respeito de sua segunda obra literária, O Sexo Portátil (1968), e sua participação em $A$ Cidade e as Ruas (1964), editada por Ruy Carvalho que incluiu o conto "A Senhora Prisca” do autor curvelano. Nos anos seguintes, haverá uma divulgação mais do "Canabrava pintor" do que o "Canabrava escritor".

Se após Sangue de Rosaura não encontramos mais publicações de contos de Canabrava - a mais recente que temos notícia é a reportagem de Newton Vieira sobre o autor em questão (cf. VIEIRA, 2011, p. 52-57), podemos ver que há um desaparecimento da sua figura de escritor e de notícias e reportagens sobre as suas publicações literárias. Sob esta perspectiva, pode ser entendido que, embora se trate de uma obra vencedora de um prêmio literário, ela não obteve ampla divulgação.

O “silenciar" a respeito da obra de Canabrava nas décadas seguintes também podem ser reveladoras desta não presença do autor e de seus livros em outros ambientes, como na ambiência da própria academia. Encontramos o volume de Sangue de Rosaura numa pesquisa a arquivos da cidade de Curvelo, consoante a lamentos da população letrada local que se ressentia do fato de ter sido Luiz Canabrava esquecido, diferentemente do que acontecera com outro escritor curvelano e contemporâneo do autor de Sangue de Rosaura, Lúcio Cardoso. Chamou-nos a tenção o fato de ter sido obra literária vencedora de um concurso nacional de relativo prestígio, primeiramente, além de outras considerações que merecem ser mencionadas no presente estudo. Por exemplo, o fato de alguns dos contos de Canabrava que integram o livro premiado terem sido previamente publicado em jornal do Rio 
de Janeiro, Jornal dos Novos, numa coluna assinada por Dinah Silveira de Queiroz.

Uma questão merece ainda ser considerada: os contos do autor, conforme classificação de Sodré, são pautados pelo elemento fantástico, pelo sombrio e pelo tom pessimista. Observando a literatura brasileira entre as décadas de 1940 e 1950, podemos pensar na massiva presença da corrente regionalista, dos anos de 1930, com suas claras influências da escola realista, cujas contribuições à literatura nacional são inegáveis, conforme José Aderaldo Castello, no livro Literatura Brasileira: origens e unidade (1500-1960), que observa, sobre a prosa de ficção:

Além de José Geraldo Vieira, Lúcio Cardoso, Aníbal Monteiro Machado e Clarice Lispector, surgem, de fins dos anos 30 e a seguir de 40 a 50, vários prosadores. São contistas, romancistas, cronistas: Lygia Fagundes Telles, Maria de Lourdes Teixeira, Fran Martins, João Clímaco Bezerra, Moreira Campos, Fernando Sabino, Autran Dourado, Guimarães Rosa; Antônio Calado, Rui Santos, O. G. Rego de Carvalho, Luiz Canabrava, Antônio Olavo Pereira, Ernâni Sátiro, Herberto Sales, Adonias Filho, Gastão de Holanda, Alceu Marinho Rego, Geraldo Santos, Ricardo Ramos, Osman Lins, Josué Montello. Destacam-se, também, com preferência pela temática da infância à adolescência e pelo fantástico, os nomes de Orígenes Lessa, José Mauro de Vasconcelos, Clara Carta, José J. Veira, Murilo Rubião, Luiz Canabrava. A Relação é longa e também em virtude dos limites que nos impomos, restringimo-nos a referências e enfoques parciais, visando apenas a sugerir o prosseguimento de tendências e constantes temáticas já amplamente exploradas, ressaltando ao mesmo tempo propostas de renovações ou inovações (CASTELLO, 2004, p. 438-439).

O mineiro Luiz Canabrava, citado ligeiramente por Castello, surge com a proposição do veio insólito na escrita, trazendo uma representação literária que não correspondia ao gosto da época, como se pode supor. Como exemplo, podemos citar o caso do também mineiro Murilo Rubião, que publica em 1947, seu primeiro livro de contos, O ex-mágico, sem grande repercussão, na época. O sucesso de Rubião como autor acontecerá somente em 1974, com a publicação de O pirotécnico Zacarias.

Em uma das poucas publicações recentes a respeito de Luiz Canabrava, Newton Vieira, em reportagem para a revista Pequi Magazine em 2011, intitulado "Luiz Canabrava: 
tão genial quanto esquecido", apresenta-nos um breve panorama da chegada do autor curvelano ao Rio de Janeiro, em 1949, até a publicação de Sangue de Rosaura em 1954:

Bagagem repleta de sonhos, Luiz Canabrava desembarcou no Rio de Janeiro. Consoante afirma Ruy Carvalho, corria o ano de 1949, um dos mais movimentados no então centro de decisões do Poder. No carnaval, luto pela morte de Paulo da Portela e dois desfiles de escolas de samba: o da FBES, considerado oficial e vencido pela Império Serrano, e o da UGS, no qual a Mangueira se sagrou campeã. Emilinha Borba, a Rainha do Rádio, arrebatava os fãs com Chiquita bacana, de Braguinha e Alberto Ribeiro, mas, ironicamente, perdia o cetro a coroa para Marlene. Aproximava-se a Copa do Mundo e as obras de construção do Estádio Mário Filho, o Maracanã, recebiam ferrenhas críticas do deputado federal Carlos Lacerda, adversário do prefeito, Ângelo Mendes de Moraes. Por falar em estádio, o Vasco da Gama levantava a taça do Campeonato Carioca, com Ademir Menezes de artilheiro. Ficava pronta a adutora da Usina de Fontes Velhas, suposta garantia de ininterrupto abastecimento de água. De fato, a vazão passava a ser de 5.100 litros por segundo a mais. No entanto, o problema não seria selecionado, e os compositores Victor Simon e Fernando Martins, em 1954, fariam esta denúncia na marchinha Vaga-lume: "Rio de Janeiro/ Cidade que me seduz/ De dia falta água/ De noite falta luz". (VIEIRA, 2011, p. 53).

Este panorama histórico da vida carioca no momento em que Canabrava chega ao Rio de Janeiro até a publicação de Sangue de Rosaura, pode parecer um contraste em relação ao que Nelson Werneck Sodré acentua no livro de estreia do escritor de Curvelo: pessimismo, dramaticidade sombria, violência. Contudo, não é o clima tenso do suicídio de Getúlio Vargas (1954) que conduz as narrativas do escritor mineiro, segundo a leitura que aqui se apresenta. A escrita de Canabrava denota um movimento de dentro para fora; a percepção de mundo apresentada por seus personagens - todos oprimidos, asfixiados pela clausura das famílias tradicionais em que vivem ou pela vigilância severa das cidadezinhas mineiras das quais anseiam libertar-se - parecem coligar-se numa unidade organicamente percebida.

Nesse aspecto, mais do que os acontecimentos externos do país, é conveniente ressaltar a questão de um mineiro que, ao sair do interior, se encontra na maior cidade do país, 
matriz cultural do momento. Luiz Canabrava leva para sua escrita sua amargura de interiorano, para quem o espaço e as limitações da tradicional cultura de Minas Gerais representam-se de forma violenta, sangrenta e claustrofóbica, como veremos no decorrer desta reflexão. A partir dessas rflexões, podemos requisitar uma percepção acerca do autor e da obra, que traz o contraste entre as culturas existentes e que opõe, de forma sutil, a abertura da capital carioca, com seu litoral, sua noite fervilhante e, de certa forma, mais condizente com um espírito de liberdade e de evasão que o clima de penumbra, fechamento e tradição que emana das montanhas de uma Minas Gerais interiorana.

O livro de Canabrava carrega essa sensação taciturna de algo remetente ao espaço de seu passado do qual ele precisa libertar-se e efetivamente o faz, fisicamente, quando se muda para o Rio de Janeiro, em 1949. É o que podemos extrair desta informação recolhida pelo Flan, o jornal da semana do período de 6 a 12 de junho de 1954, que traz uma reportagem exclusiva com Luiz Canabrava pós-vitória no Prêmio Fábio Prado:

A história de "Sangue de Rosaura", o livro premiado, tem o seu lado pitoresco. Canabrava trabalhava na loja "Sears", como desenhista do departamento de publicidade. Desenhava gravatas, colarinhos, camisas, suéteres, o que mandassem, para ser publicado nos jornais. Os patrões estavam satisfeitíssimos, os colegas admiravam-no - o artista aprovava. Tanto que o gerente um dia o chamou para dizerlhe que ia dar uma ordem para aumentarem-lhe o salário. O artista saiu do gabinete do chefe abatido sem saber o que fizesse. A inscrição do "Fábio Prado" estava aberta, os colegas animavam-no a concorrer - ele queria com todas as forças de sua vocação participar do concurso. A obrigação da loja era cada vez mais absorvente: passava o dia desenhando, desenhando. Aquele trabalho se agradava ao patrão, a ponto de oferecer-lhe um aumento, não o satisfazia: devia deixá-lo, quanto antes e dedicar-se à sua literatura, à sua ficção. $\mathrm{E}$ tinha de ser logo, antes de receber o aumento que poderia ser grande a ponto de prendê-lo definitivamente à loja. Não teve dúvida: largou tudo e tomou um trem rumo a Minas Gerais, onde passou vinte dias. De volta, trazia o "Sangue de Rosaura", imediatamente enviado à comissão julgadora do "Fábio Prado". O resultado está aí: 25 mil cruzeiros e notoriedade.

- Depois do livro escrito - diz-me Canabrava - novamente apareceu a questão da sobrevivência. O estômago reclamava e fui obrigado a alugar temporariamente a minha alma ao diabo!... Entretanto, espero, mais cedo ou mais tarde, dedicar-me às minhas histórias, 
porque não sou capaz de fazer literatura nas horas vagas. Só posso escrever com muito tempo disponível. (MEIRA, 1954, p. 6, grifo nosso).

Podemos entender essa passagem da vida de Canabrava como fundamental para seu ingresso na arte do livro: da ilustração pela imposição da sobrevivência, na capital do país, parte de volta ao seu lugar de origem, objetivando a organização da obra que concorreria ao prêmio literário. O trecho em negrito destaca este retorno a Minas Gerais como parte do processo de composição do livro.

Acreditamos que tal viagem seria também uma sugestão simbólica a um retorno ao interior de si, pois o livro Sangue de Rosaura apresenta uma visão de Minas Gerais a partir de uma percepção interiorizada - tanto ao espaço predominante rural das narrativas, quanto das representações introspectivas presentes nas personagens e nos contos da obra.

Com o prêmio, consegue levar ao público sua criação, editada pela José Olympio, que assim aparece na primeira impressão:

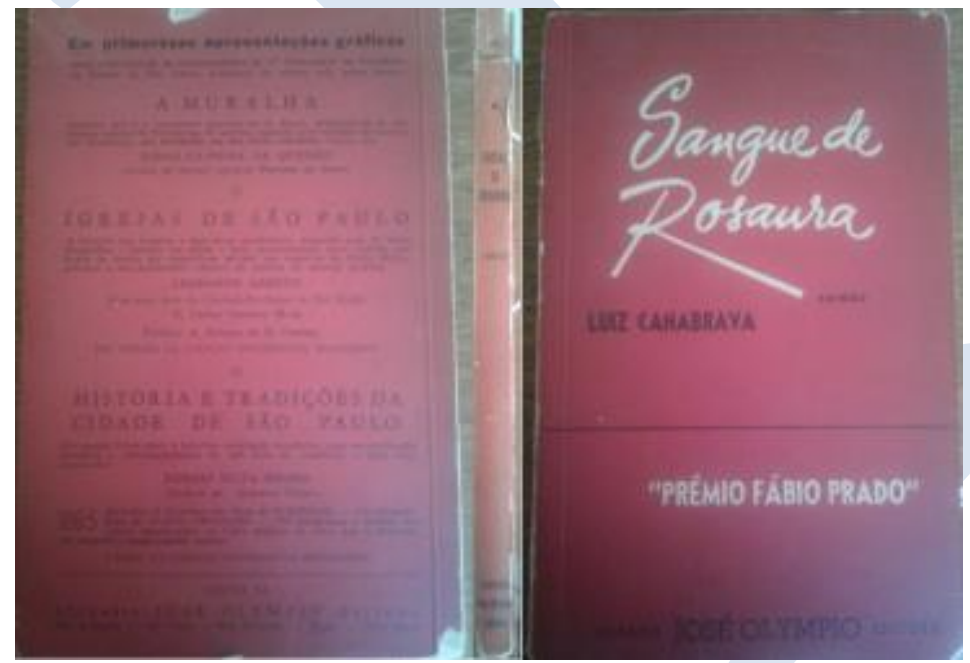

FIGURA 2: Contracapa, lombada e capa de Sangue de Rosaura FONTE: CANABRAVA, 1954 
Sobre a concepção da capa, de design simples, mas de cor vermelho sangue, não podemos perder de vista o fato de que o autor em questão era desenhista, artista plástico. Todos os contos do livro são acompanhados de ilustrações feitas pelo próprio Canabrava. A cor da capa não seria atribuída ao mero acaso, portanto. Se pensarmos no objeto livro, em sua completude, encontraremos algo mais do que as histórias que ele conta: tudo o que o circunda, capa, orelhas, título, tipos de letras, concepção editorial, diagramação também dizem ao leitor sobre o livro e de seu autor.

Partindo de tais reflexões, “o sangue de Rosaura”, imagem que chega ao leitor desde a capa e o título, estaria em toda a obra, perpassando por todas as narrativas. $\mathrm{O}$ fato de o primeiro conto do livro ser justamente "Sangue de Rosaura" soa como uma espécie de introdução para as demais narrativas ou como uma linha interpretativa previamente traçada que favorecesse a ideia de que o sangue, a morte, o medo e o pessimismo pudessem constituir uma escrita organicamente agrupada.

Embora não possamos confirmar a intenção de Luiz Canabrava ao denominar sua coletânea de contos de estreia com o nome de um dos seus contos, podemos pressupor algumas ideias acerca de como tal composição pode ser entendida como parte da elaboração de uma obra literária. Assim, o que traz a primeira impressão acerca da ideia do que se trata o Sangue de Rosaura é o que podemos ter na recepção da capa do livro: uma ideia de que os dez contos — nesta devida sequência: "Sangue de Rosaura", "Maria Bambá", "Noite”, “O colecionador de quinquilharias”, "Isaltina”, “O Bruxo”, “João Peba”, "O buraco", "O menino" e "A espera" — estariam marcados por esse "sangue", que conduziriam o leitor a uma atmosfera decadente, aprisionante e pessimista, conforme discutiremos ao longo deste estudo.

A disposição de tais contos parece encaminhar para a percepção de que o "sangue de Rosaura" — termo não só constante no título, mas também no primeiro conto — escorre pelos demais, compondo uma coletânea de contos que não parece ter sido selecionada a esmo, com o fim objetivo de concorrer a um prêmio, mas previamente organizada a partir de uma unidade de sentido. 
Os livros são objetos de linguagem, são matrizes de sensibilidade. Criar livros implica determinar relações com outros códigos e, sobretudo, apelar para uma leitura sinestésica com o leitor. A importância da imagem, do traço, da cor, da montagem, da diagramação e de todos os elementos correspondentes à feitura material do livro, constitui uma finalidade criativa que sustenta tanto a forma quanto o significado. Luiz Canabrava, que mais dedicou sua vida à ilustração e à pintura do que a escrita, pode ter se preocupado tanto na elaboração da capa assim como se dedicou a ilustrar os contos, o que lhe confere, em um mesmo objeto, duas facetas artísticas: a do escritor e a do artista plástico.

Essa reflexão acerca da atitude ativa do autor/artista de livros pode ser estendida à relação do leitor/observador com o livro, e sua interação com o objeto livro é parte importante da sua significação, seja referente ao seu manuseio, explorando as possibilidades do objeto, seja envolvendo a percepção do conteúdo, a leitura e a interpretação dos significados.

O livro, assim, é o resultado de uma experiência não apenas artística no campo textual, mas também do além-dele, do paratextual. Portanto, entendemos Sangue de Rosaura como uma realização de Luiz Canabrava em vários aspectos artísticos, tanto no aparato textual quanto no visual. Por meio de um conto, ele dá título ao livro e propõe uma interpretação que torna possível o conceber de seu livro como uma obra.

Tomemos para análise o primeiro conto do livro e aquele que também dá título ao livro: "Sangue de Rosaura". No primeiro parágrafo, podemos entender que, assim como na ilustração, há no texto uma figura que se esconde, na cama, à espreita, de olhos abertos:

Rosaura tomava café, requentado no fogareiro. Cessou o tintilar da xícara e do pires, veio o ruído da chave na fechadura. Por economia, Rosaura não acendia a luz, agia na obscuridade. Bateu o portão da entrada, vieram os passos de Rosaura no passeio, pequenos, cadenciados, lá se foi ela, de braços cruzados, encolhida por causa do frio, segurando o terço debaixo do paletó surrado, o nariz vermelho, tiritando.

"Devo dar-lhe uma navalhada no pescoço — pensa Adão. - É isto mesmo, hei de decepar-lhe a cabeça e expô-la na vitrina da "Casa Minerva", embrulhada em papel impermeável e com os quindins da Fábrica em volta". 
Agita-se debaixo do cobertor, coça a perna, boceja. (CANABRAVA, 1954, p. 11)

A construção deste trecho mostra-nos uma figura que esconde as suas intenções, embora perscrute todos os movimentos da personagem Rosaura. Rosaura, a personagem título, segue um ritual para depois dedicar-se à religiosidade. Oculto, Adão, que estava enrodilhado na cama, planeja não um simples assassinato, mas uma exposição do crime, uma exposição do sangue. Até aqui, ilustração e texto confluem em um expor do que é vital de forma macabra, a pressupor uma ideia de situação de horror, de desgraça. Mesmo virulento, Adão permanece numa atitude passiva, agitado dentro do cobertor e afetado pelo acordar da fria manhã.

Contudo, a inibição ainda não é o suficiente para que ele desfaça essas ideias de homicídio:

\begin{abstract}
"Depois, será preciso extrair-lhe o sangue do corpo, reparti-lo em recipientes de prata, que serão colocados, cuidadosamente, um a um, em várias esquinas, para alimentar os vira-latas. Não deverei esquecer-me do aviso, escrito com letras bem gordas: SANGUE DE ROSAURA".

Adão fecha os olhos e trinca os dentes, de raiva. Seu último motivo é que Rosaura não quer saber dos menininhos chineses, cheios de percevejos nos cabelos sujos e perebas nas pernas. Mas essa raiva não é recente, vem do tempo em que Adão era menino, raiva que era também de Josefina e Irene, muito mais de Rosaura, que gostava dele. (CANABRAVA, 1954, p. 11).
\end{abstract}

O mote da narrativa é declarado em letras garrafais: o que se objetiva por aqui é o sangue de Rosaura pela parte de Adão. Não é um sangue que é oculto pelo corpo e mantém a vida, mas sim exposto, se possível que mostre até as vísceras, e que todo mundo veja e reconheça a quem pertence aquele sangue. Se possível, que sirva de alimento até mesmo para os cachorros, como uma prazerosa forma de apreciar o assassinato.

Tal fato é o que leva Adão a se encolher em sua própria raiva. O que vem dele as ideias sobre os "menininhos chineses cheios de percevejos" - é negado por Rosaura, e fomenta a sua raiva com relembranças da infância. Identificamos que a narrativa condiciona nestes instantes algumas maneiras para tentar tornar Adão como vilão da narrativa. É posto 
que ele sente muito mais raiva de Rosaura do que de Irene e Josefina, mas que Rosaura era a que mais gostava dele.

Essas relações evocam diretamente tudo o que possui sangue e vida e colocam em evidência as questões da consanguinidade. Irene agride o sobrinho, mas Rosaura e Josefina apresentam relações da ordem dos mais diversos motivos: a primeira, em relação aos cuidados; a segunda, repetindo um lamento acerca de um menino que existe pelo pecado, enquanto que ela é uma virgem. Em Rosaura, cresce uma ligação com Adão de forma a suprir qualquer necessidade que a criança tenha pelo zelo. E conforme continua o narrador, passa a ser um cuidado exacerbado:

Rosaura tinha medo de tudo. Do vento que zunia com força nos dias de chuva, das leves brisas que sopravam no jardim dos fundos, dos bois que, de vez em quando, pastavam nas ruas, das almas penadas, dos homens, sim dos homens! Seu Manuel da venda era ruim feito cobra. Bebia, fazia farras, batia na mulher. Bento, irmão de Etelvina, rapaz desordeiro. O juiz-de-direito, o sapateiro, Juca do Açougue, Domingos de Feliciana... não punha a mão no fogo por nenhum deles. De homem, só o padre José das ladainhas, das procissões da Semana Santa e da festa de S. Nepomuceno, só o padre José que já nem era homem, de tão santo.

$[\ldots]$

Josefina amaldiçoou mil vezes a sem-vergonhice da mulata mãe dele e o pecado do irmão Rodrigo, chorou suas louças quebradas, quis benzê-lo para lhe tirar o diabo do couro. (CANABRAVA, 1954, p. 13-14).

Ligada à religiosidade, Rosaura tem medo da vida e de todas as suas manifestações. Trata o menino sob a batuta dessa religiosidade cheia de pecados e limites. Não permite que os outros humanos (os de sangue vivo) tenham alguma relação com Adão, exceto o padre, que ela considera um santo, alguém que vai além da carne, além do sangue.

É nesse tom que há a sequência da narrativa: vemos o personagem principal lidar com as maldades que tanto há na imaginação como há na realidade em que se situa. A narrativa segue com uma descrição da adolescência até a vida adulta de Adão, que, embora fosse uma criança bem vivida, era protegido por Rosaura, a ponto de ficar em casa por 
decisão dela, até que surgisse uma oportunidade de emprego. E Adão começa a sentir as limitações por sempre necessitar de dinheiro por parte da tia:

Excitado com o início do assunto que há muito acalentava, ele insistiu:

— Não estou brincando, não, Rosaura. Nós encheríamos de gente...

- Para, Adãozinho! Você está maluco?

- O mar, Rosaura, eu nunca vi o mar! E tem a Finlândia, a Nova Zelândia, os Alpes Suíços e o reinado do Sião...

Rosaura repreendeu-o com tanta energia por causa dessa ideia, que Adão esmoreceu, pensando no preço incalculável do transatlântico "Queen Mary".

Depois de muitos meses, durante os quais ele se tinha tornado bem mais modesto, voltou ao assunto que o atormentava:

- Rosaura, me dá uma passagem para a Europa? Eu aproveitaria, estudaria, minha vida teria algum significado...

- Nunca! - respondeu Rosaura, ainda achando que era brincadeira.

— Mas é a minha vida, Rosaura! Minha vida. Que adianta o dinheiro no Banco?

- Adãozinho, para! Você deixa de fantasia, este mundo não vale nada, o que vale é só o amor de Deus.

- Rosaura, então uma viagem ao Rio de Janeiro. Lá tem mar.

Rosaura, amuada, nem enxergou as lágrimas que brotavam da ansiedade dele, e pintou o Rio tão perigoso, que Adãozinho ficou com medo e aquietou-se (CANABRAVA, 1954, p. 16-17).

Podemos ver que amargura de Adão parte da inércia do local em que ele está. Ele deseja buscar um mundo diferente daquele que vê no dia-a-dia e no qual está preso. Rosaura é quem o atrapalha, com a desculpa de que a única coisa que importa é manter o "amor de Deus", a religiosidade, o valor das tradições locais (as ladainhas, procissões e festas do padre). A Finlândia, a Nova Zelândia, os Alpes Suíços, o Reinado do Sião, a Europa e o Rio de Janeiro soam distantes da realidade dele, que não o deixa construir conhecimento e, curiosamente, não o deixa ver o mar, libertar-se.

Na forma como a tia Rosaura o trata, o diminutivo Adãozinho, lemos não uma notação carinhosa, afetiva, mas uma extensão dessa prisão consanguínea, religiosamente fervorosa e limitadora, uma apropriação que o diminui e o humilha. Não podemos deixar 
de evocar que, na casa onde vivem três mulheres solteironas, ele é o único homem, como o próprio nome anuncia, o "Adão", mas se encontra sufocado em sua virilidade, sua liberdade e pela falta de dinheiro, que também lhe era negado.

\begin{abstract}
Olha para um lado, depois para o outro. Nunca mais quer se encontrar com Rosaura e a única saída é a porta da cozinha. Lança-se na direção dela, empurra-a, desvairado, sente um baque, ouve um grito e repinicar de louça no chão.

$[\ldots]$

Adão olha-a, impassível, embora seus olhos chorem. Choram simplesmente, sem qualquer sentido de dor, nem de alegria. Só pensa: "Amanhã, essas duas idiotas, Josefina e Irene, se esquecerão de Rosaura. Amanhã, a gente saberá do testamento e eu, certamente, herdarei pelo menos metade das ações da "Fábrica de Quindins", apesar disto me ser completamente indiferente. Amanhã, o sangue de Rosaura será outra coisa e a sua cabeça também".

Está esquecido dos menininhos chineses, tão distantes os pobres meninos, do transatlântico "Queen Mary", das ilhas dos mares do sul. A única vontade que o domina, sem dúvida, é ficar em casa para sempre, à toa, pensando à toa. (CANABRAVA, 1954, p. 19-20).
\end{abstract}

Em apenas um ato, Adão realiza dois desejos: o da fuga e o de atacar Rosaura. Porém, é um ato que falha, pois ao trombar com a tia, ela acaba por desmaiar e morre. A fuga não tem o seu desenlace, pois, ao final, ele desiste de fugir; ele tromba com a tia, porém não é o responsável pela morte dela. Sem conseguir realizar esses dois desejos, à Adão ocorre a imobilidade. Ele desiste de todos os seus planos de vida apenas para ficar à toa, a esperar pela herança que Rosaura tem para lhe oferecer. Sem mais o mote de sua vida, não há como continuar a sua narrativa de vida, o seu conto, e assim a história se encerra.

Podemos depreender, assim, que o "Sangue de Rosaura” é marcado pela questão ligada à família e pela opressão que a vida familiar causa. Em relação aos familiares, há uma relação em que alguém é subordinado e massacrado em sua identidade, e esta condição o leva ao ódio e ao desejo da morte. Embora rejeitado por Irene e Josefina, é a morte de Rosaura que ele deseja, supostamente a morte da tia que o tivera mais próximo, ao lado da cama. Ela não só o mantém preso no espaço claustrofóbico da casa, mas o limita e cerceia pelas questões moralizantes da religiosidade excessiva. 
Se em "Sangue de Rosaura" há uma diminuição da masculinidade de Adão, conforme a tia Rosaura o chama por Adãozinho, podemos ver, em outros contos do mesmo livro, esta tendência da revisão da ideia do homem mineiro como um ser másculo, viril, heterossexual. Em “O Colecionador de Quinquilharias”, José, o personagem principal, preocupa-se com a chegada do irmão, e atém-se a um baú em que guarda os mais variados objetos, a retomar peculiares situações:

Desde muito tempo, desde pequeno. Era bom o estalar das folhas sob os cascos dos cavalos, o prurido debaixo dos lençóis depois da sarabanda da chuva, o tempero exalado da comida de Lavínia, o rosto do irmão adomercido. Melhor ainda era amar mulher desacordada e gostar dos amigos mortos. Fora tão perfeito o beijo na boca de Conceição, ferida na cachoeira, o sangue ainda quente nos seus lábios abertos. Seu vestido era belo, colado na carne firme, e nele mesmo, era mais belo o rorejar do suor na testa e o cabelo se agitando na brisa.

Depois, foi Frederico, morto aos seus pés, sujo de terra, tão calmo e tão criança, que só pode mesmo abaixar-se com um aperto na garganta e ficar, por muito tempo, abraçado a ele, com o rosto apertado no seu rosto inerte (CANABRAVA, 1954, p. 52)

Esta passagem ilustra as descobertas mais marcantes de José, ainda na infância, pelo desejo: o beijo na boca de Conceição, o abraçar do corpo morto do amigo Frederico, são os seus primeiros contatos em relação ao desejo. O contato com a mulher se concretiza; já o com um homem é impossível, e resta à José apreciar o corpo do morto, a abraçá-lo, a apertar em seu rosto, pois, naquele momento, apenas por meio da morte é que poderia exercer o desejo pelo corpo de um semelhante.

Ainda em "O Colecionador de Quinquilharias", a versão publicada em Sangue de Rosaura há um acréscimo substancial na história de José: após fugir da fazenda ante a chegada do irmão, há um corte na narrativa e o encontramos nas ruas, a viver como um mendigo. Ele acaba sendo encontrado pela sua tia Jacira e o filho desta, Eduardo. Então se segue uma cena curiosa: Eduardo dá banho no primo, e José veste a roupa deste parente: 
Os meninos, amontoados no corredor, olham curiosos, quando José aparece no meio de um cheiro gostoso de sabonete e água morna. Está limpo, calmo, com o olhar deslumbrado, meio desengonçado dentro da roupa de Eduardo, que ficou grande.

- Agora, sim! Virou outro. Está limpo e satisfeito, vai comer um arroz com carne que eu preparei - anima-o a tia.

— Como vai, José? - pergunta Oscar, tentando um ar brincalhão. - Vou bem. - ele responde.

Ninguém repara quando Eduardo sai, nervoso, de cabeça baixa (CANABRAVA, 1954, p.54)

$\mathrm{O}$ ato de um homem banhar outro homem sugere um contexto homossexual: um homem possui o outro, tem na figura masculina alheia a função de remover as suas impurezas, de possuir seus bens, de ser reestabelecido em sua função dentro de um contexto. José, recuperado, banhado e limpo, volta a ser um mineiro exemplar, enquanto que o primo, nervoso, entra em contato com a sua "sujeira", a se sentir estranho, diferente em seu meio.

Este trecho parece ter ainda mais importância quando o comparamos com sua primeira publicação. No Jornal dos Novos, em 1950, Canabrava publicaria “O Colecionador de Quinquilharias”, em 24 de setembro, não há esta cena extra. Este substancial acréscimo pode ser apontado como uma das primeiras incursões de Luiz Canabrava em uma literatura sobre a homossexualidade, pelo menos de forma explícita. Se em "Sangue de Rosaura" vemos a diminuição da figura masculina, enquanto perfeito arquétipo de virilidade, encontramos em "O Colecionador de Quinquilharias" uma masculinidade represada, apenas com vestígios de um desejo sexual entre iguais.

Ainda no livro Sangue de Rosaura, podemos pensar em outras possibilidades da representação do ideal masculino viril em xeque: no conto "Isaltina”, há referência há um rapaz que é descrito como "afeminado" pelo narrador. Em "O Bruxo", o personagem Cristiano fica subjugado à figura de um feiticeiro dentro do próprio quarto. Em "A Espera", Benedito diz à Olivério que "mulher é que não fuma". Tais passagens evidenciam que Canabrava ensaiou algumas de suas ideias em relação à questão do ideal masculino viril 
heterossexual, deixando expressas representações de outras manifestações de desejo e erotismo.

O "sangue" que jorra da capa do livro para as expressões de violência, medo, aprisionamento e pessimismo, constantes em todos os contos do livro identificam a amargura de um autor-narrador, que, emerge, simbólica e literalmente, de uma Minas Gerais interiorana, católica e repressora, para uma escrita que se manifesta, nesta primeira tentativa, como evasão e libertação.

Catorze anos depois, em 1968, o autor de Curvelo publicaria dois trabalhos que apresentam as relações sexuais entre homens como tema: "Aprendizado", incluído na coletânea Histórias do Amor Maldito (1968), organizada por Gasparino Damata, sobre um garoto de programa chamado Túlio (cf. CANABRAVA in DAMATA, 1968, p. 109-119); e O Sexo Portátil (1968), romance que conta a história de Camilo, um rapaz que nascera na fictícia cidade mineira de Mata da Corda e se relaciona com homens no Rio de Janeiro.

Anos mais tarde, no livro organizado por José Carlos Honório O Amor com Olhos de Adeus (1995), temos uma das últimas narrativas que se tem notícia de Canabrava publicada em vida: "O Anjo da Avenida Atlântica”, sobre um garoto de programa que atua na referida avenida do Rio de Janeiro do título (cf. CANABRAVA in HONÓRIO, 1995, p. 155-163).

Denilson Lopes, em artigo intilulado "Brazil, Literature", publicado no livro Routledge International Encyclopedia of Queer Culture (2011), coloca Canabrava como um nome importante na literatura brasileira com personagens homossexuais na segunda metade do século XX:

Durante a década de 1960, as ruas das cidades do Brasil eram um espaço de visibilidade para os personagens homossexuais cujas identidades tomaram uma forma libertária, em que os homossexuais eram retratados de maneira neo-naturalista, que misturava questões de sexualidade com questões sociais, econômicas e políticas. Esses trabalhos surgiram no contexto de um país em que as sombras de um regime autoritário assumiram o surgimento do golpe militar de 1964. Autores como Gasparino Damata (1918-82), Luiz Canabrava (1926) e Aguinaldo Silva (1944-) apresentam uma narrativa direta e realista para procurar uma imagem que seja mais ampla do que a 
negação do desejo sexual. Esta literatura registra a realidade social através de uma fascinação intelectual para os marginalizados. (LOPES in GERSTNER, 2011, p. 102, tradução nossa). ${ }^{12}$

O que levaria Canabrava a sair de uma temática de narrativas sobre situações sombrias em cenários mineiros a retratar a vida de personagens homossexuais no Rio de Janeiro? Em “O Colecionador de Quinquilharias", José almeja fugir para a então capital do Brasil como uma forma de escapar dos compromissos familiares, locais.

Em Sangue de Rosaura veríamos também a representação da fuga de Luiz Canabrava de Minas Gerais para o Rio de Janeiro? Essa fuga significaria uma abertura, após o sangue derramado, isso é, sua tentativa de purificação, para, então, passar a dedicar-se aos temas homossexuais?

Pensando nesta perspectiva, lembramos a proposta de outro autor também nascido na cidade mineira de Curvelo: Lúcio Cardoso, mais conhecido pela Crônica da Casa Assassinada (1959), que traz neste denso romance uma situação trágica a envolver os integrantes de uma tradicional família mineira.

Ésio Macedo Ribeiro, em sua organização dos Diários (2012), traz o "Depoimento" que Cardoso dá à Faustão Cunha para a edição de 25 de novembro de 1960, em que se lê o seguinte manifesto:

Meu movimento de luta, aquilo que viso destruir e incendiar pela visão de uma paisagem apocalíptica e sem remissão é Minas Gerais. Meu inimigo é Minas Gerais.

O punhal que levanto, com a aprovação ou não de quem quer que seja é contra Minas Gerais.

Que me entendam bem: contra a família mineira. Contra a literatura mineira. Contra o jesuitismo mineiro. Contra a religião mineira.

\footnotetext{
${ }^{1}$ During the 1960s Brazil's city streets server as a space of visibility for gay characters whose identities took shape in a libertarian fashion in which gays were portrayed in a neo-naturalist way that mixed questions of sexuality with social, economic and political issues. These works emerged against a backdrop of a country in which the shades of an authoritarian regimen took hold following the military coup of 1964. Authors such as Gasparino Damata (1918-82), Luiz Canabrava (1926-), and Aguinaldo Silva (1944-) present a direct, realist narrative to search for an image that is broader than the denial of sexual desire. This literature registers social reality through an intellectual fascinaton for the outcast.
}

${ }^{2}$ Erroneamente, Lopes coloca Canabrava ainda vivo. Luiz Canabrava morreu em 2000. 
Contra a concepção de vida mineira. Contra a fábula mineira. Contra o espírito judaico e bancário que assola Minas Gerais. Enfim, contra Minas, na sua carne e no seu espírito (CARDOSO, 2012, p. 731).

Embora não saibamos comprovadamente se Lúcio Cardoso e Luiz Canabrava tenham se encontrado de alguma forma, ambos são mineiros, nascidos na interiorana cidade de Curvelo e viveram no Rio de Janeiro, na mesma época. São artistas, escritores, pintores, homossexuais. A escrita de ambos denuncia a amargura de uma origem marcada pela mordaça e pelo preconceito. O que o autor de Crônica da Casa Assassinada propõe é o que parece que vemos realizado em Sangue de Rosaura. Assim como na obra de Cardoso, o livro de Canabrava mostra uma essência destrutiva que apresenta uma Minas Gerais sombria, fantasmagórica, que impõe o mal aos seus habitantes e os condena a terríveis destinos.

\section{Considerações finais}

A adoção de temas sombrios em Minas Gerais em contraste com a predileção à homossexualidade nas suas narrativas "cariocas" pode apontar para um conflito presente nas narrativas e nos desenhos de Canabrava. Entendemos Sangue de Rosaura como uma representação do que há de mais soturno em Minas Gerais e nos mineiros: é o preconceito contra o outro; é a condenação à morte para qualquer tipo de amor que não seja o imposto pela sociedade mineira, é a sujeição e o domínio de quem é diferente. Assim, os sentimentos que unem o livro são o desejo de destruir, de ocultar, de silenciar contra o qual se rebelam as personagens.

O sangue — que representa esse ódio libertador — identifica o livro Sangue de Rosaura como uma alegoria ao espaço de Minas Gerais, simbolizada pelo que escorre das feridas abertas pelas narrativas canabravianas. A tendência de uma literatura homoerótica, apenas delineada na obra premiada, vai ser explicitada em Sexo Portátil, mais clara, mais enfática, obra escrita em outro Brasil e com outras circunstâncias. 


\title{
TRADITION AND DESIRE LUIZ CANABRAVA'S WORK
}

\begin{abstract}
Published in 1954 by José Olympio publishing house, Sangue de Rosaura, a collection of short stories by writer Luiz Canabrava, brings out homoeroticism characteristics. Despite winning a national literary award, the book made little impact and went almost unnoticed. Representations of violence, sorrow and imprisonment, consistent elements in the narratives, conjoint the expressions of restrained homoerotic desires. Referred to as a precursor to Brazilian homoerotic literature, from 1960's onwards, the mineiro writer from Curvelo had already begun to delineate situations in which the virile male figure not only goes into decline, but points out to an expression of sexual desire between two men as well. Aiming to reinstate this forgotten writer to his rightful place as an important author for Brazilian LGBTT literature in the mid-20th century, we investigated how Canabrava, even in his debut, brings out the homoeroticism theme, and how that could have been one of the reasons for the authors removal from Brazilian literary historiography.
\end{abstract}

KEYWORDS: Homoeroticism; Literature from Minas Gerais; Luiz Canabrava; Sangue de Rosaura;

\section{Referências}

PANORAMA LITERÁRIO. IN: Letras e Artes. Rio de Janeiro, p. 10, 29 de Junho de 1954. PANORAMA LITERÁRIO. IN: Letras e Artes. Rio de Janeiro, p. 11, 1º de Junho de 1954. PANORAMA LITERÁRIO. IN: Letras e Artes. Rio de Janeiro, p. 11, 17 de Agosto de 1954. BOTELHO, Cristina; FERREIRA, Luciana Cavalcanti. Crítica Literária: Conceito e Evolução. Disponível em: http://www.facho.br/downloadDoc.php?d=arqArtigo\&f=travessia2010_letras01.pdf. Acesso: 29-09-2016 14h34min.

CANABRAVA, Luiz. Aprendizado. IN: DAMATA, Gasparino. Histórias do Amor Maldito. Rio de Janeiro: Gráfica Record Editora, 1968, p. 109-119.

CANABRAVA, Luiz. O Anjo da Avenida Atlântica. IN: HONÓRIO, José Carlos. O Amor com Olhos de Adeus: antologia do conto gay brasileiro. São Paulo: Editora Transviatta, 1995, p. 155-163.

CANABRAVA, Luiz. Sangue de Rosaura. Rio de Janeiro: José Olympio, 1954.

CARDOSO, Lúcio. Diários. Organização, apresentação, cronologia, estabelecimento de texto e notas de Ésio Macedo Ribeiro. Rio de Janeiro: Civilização Brasileira, 2012.

CASTELLO, José Aderaldo. A Literatura Brasileira: origens e unidade (1500-1960). São Paulo: Edusp, 2004

LOPES, Denilson. Brazil, Literature. IN: GERSTNER, David A. Routledge International Encyclopedia of Queer Culture. New York, NY: Routledge, 2011.

MEIRA, Mauritônio. Mineiro (Tímido) de Curvelo Ganha o "Prêmio Fábio Padro". IN: 
Flan - O Jornal da Semana. Rio de Janeiro e São Paulo, p. 6, 6-12 de junho de 1954.

SODRÉ, Nelson Werneck. Sinais de Derrota. IN: Pensamento e Arte. São Paulo, p. 3 e 5, 25 de dezembro de 1954.

VIEIRA, Newton. Luiz Canabrava: tão genial quanto esquecido. IN: Pequi Magazine. Curvelo, v. 4, n. 5, 2011, p. 52-57.

Recebido em: 15/09/2017. Aprovado em: 23/11/2017. 